\title{
The Importance of Adjuvant Agents in Acute Intrathecal Baclofen Withdrawal: Case Report and Review of the Literature
}

\author{
Christopher M. Wang, Susan E. Opper
}

Department of Anesthesiology, University of Missouri-Kansas City, School of Medicine, Kansas City, USA.

Email: wangchris@umkc.edu

Received July $9^{\text {th }}$, 2012; revised August $10^{\text {th }}, 2012$; accepted August $28^{\text {th }}, 2012$

\begin{abstract}
Objective: Baclofen ( $\beta$-p-chlorophenyl-GABA) selectively activates the $\mathrm{GABA}_{\mathrm{B}}$ subtype of $\gamma$-aminobutyric acid (GABA) receptors, a group of receptors known to provide inhibitory neurotransmission in the central nervous system. Available for over thirty years in oral form for the treatment of skeletal muscle spasticity, its availability now includes continuous intrathecal infusion via an internally implanted pump. While ideal for long-term attenuation of symptoms, this treatment modality can also become disastrous should the pump empty and withdrawal subsequently ensue. Case Report: A 48-year-old male with a past medical history of T8 spinal cord injury from a motor vehicle crash originally presented with altered mental status. Because of resultant paraplegia and spasticity from his injuries, a neurosurgeon implanted an intrathecal baclofen pump three years prior to presentation with symptomatic relief. Further exploration revealed that he had missed his scheduled pump refill appointment and interrogation of his pump confirmed a completely empty reservoir. The patient endured a protracted hospital course that included rhabdomyolysis, acute renal failure, lactic acidosis, respiratory failure, and systemic inflammatory response syndrome. Treatment included benzodiazepines, dantrolene, aggressive hydration, opiates, and refill of his intrathecal baclofen pump. His mentation and ventilatory status improved with recovery from his critical illness and eventual discharge. Conclusions: Treatment of intrathecal baclofen withdrawal should focus on restoration of previous intrathecal baclofen levels by refill of the intrathecal pump. Adjuvant medications such as benzodiazepines, propofol, cyproheptadine, dantrolene, tizanidine, and opiates may prove crucial in helping with muscle spasticity while these levels are reestablished. A high index of suspicion, leading to timely initiation of proper treatment, may serve as the most important factor in successful recovery from this life-threatening syndrome.
\end{abstract}

Keywords: Baclofen; GABA; GABA $A_{\mathrm{B}}$; Intrathecal; Implantable; Infusion Pump; Chronic Pain; Pain Management; Spasticity; Spinal Cord Injury; Neurosurgery; Withdrawal; Analgesia

\section{Introduction}

Numerous articles have demonstrated the role of $\gamma$-aminobutyric acid (GABA) as an inhibitory neurotransmitter [1-3]. GABA acts at three distinct pharmacologic classes of receptors: $\mathrm{GABA}_{\mathrm{A}}, \mathrm{GABA}_{\mathrm{B}}$, and $\mathrm{GABA}_{\mathrm{C}}$ [4]. Studies have demonstrated the highest density of $G_{A B A}$ receptor sites in the mammalian central nervous system occupy the molecular layer of the cerebellum, the cerebral cortex, the thalamic nuclei, the interpeduncular nucleus, and the dorsal horn of the spinal cord [2,3]. GABA $\mathrm{B}_{\mathrm{B}}$ receptors have both pre- and post-synaptic activity in the brain, providing a viable explanation for the variety of effects seen by the subsequent hyperpolarization of neurons and/or inhibition of neurotransmitter release after receptor activation [5]. GABA, along with $\mathrm{GABA}_{B}$ re- ceptors, also reside peripherally in the small intestine, uterus, spleen, and lung, suggesting the possibility that pharmacologic agents could potentially target these peripheral sites of action as well [6].

Baclofen ( $\beta$-p-chlorophenyl-GABA) selectively activates $G_{A B A_{B}}$ receptors [7]. It produces antinociceptive sequelae through multiple mechanisms: reduction of pain associated with muscle spasm, inhibition of sympathetic output in spinal pathways, attenuation of neuropathic pain, and negatively affecting the neuronal transmission of pain [7]. Baclofen received Food and Drug Administration approval for the treatment of spasticity in 1977 [8]. Approval for intrathecal administration occurred in 1992 for spasticity of spinal origin and in 1996 for spasticity of cerebral origin [9]. Its principal clinical effect, skeletal muscle relaxation and spasticity relief, results 
from the reduction of neurotransmitter release onto motor neurons in the ventral horn of the spinal cord [10]. Baclofen also exhibits direct presynaptic inhibitory action in the superficial dorsal horn of the spinal cord, inhibiting nociceptor activity and release of sensory transmitters $[11,12]$. These transmitters include glutamate along with tachykinin peptides such as substance P [11,12]. Studies also suggest that adrenergic, dopaminergic, and serotonergic pathways help mediate baclofen's effect [13-15]. Despite its common use for muscle spasticity, baclofen appears to act through a wide variety of antinociceptive mechanisms.

We present the case of a patient with a surgically implanted intrathecal baclofen pump for control of lower extremity spasticity following a motor vehicle accident which resulted in a T8 spinal cord injury and subsequent paraplegia. Following initially excellent results from the intrathecal baclofen, an unfortunate lack of follow-up in another pain clinic resulted in an unintended empty pump reservoir and consequent profound withdrawal symptoms. The patient endured a protracted hospital course that ultimately and fortunately resulted in recovery of baseline mental and physical status.

\section{Case Report}

A 48-year-old Caucasian male presented to the emergency department as a transfer from an outside facility with a chief complaint of altered mental status. Significant past medical history included a previous motor vehicle crash resulting in a T8 spinal cord injury with ensuing paraplegia and spasticity. This required the implantation of an intrathecal baclofen pump for control of the patient's lower extremity muscle spasticity. Aside from a neurogenic bowel and bladder resulting from the injury, his other significant medical problems included only hypertension and non-insulin-dependent diabetes mellitus on minimal medications.

On admission, the patient's vital signs noted a temperature of $100.5^{\circ} \mathrm{F}$, pulse of $140 \mathrm{bpm}$, respiratory rate of $20 \mathrm{bpm}$, blood pressure of 98/57 $\mathrm{mmHg}$, and oxygen saturation of $95 \%$ on $6 \mathrm{~L}$ of nasal oxygen. Significant initial laboratory values included potassium $6.6 \mathrm{mEq} / \mathrm{L}$, bicarbonate $19 \mathrm{mEq} / \mathrm{L}$, serum creatinine $3.4 \mathrm{mg} / \mathrm{dL}$, white blood cell count 13,400 cells/ $\mu \mathrm{L}$, hemoglobin $11.2 \mathrm{gm} /$ $\mathrm{dL}$, creatine kinase $357 \mathrm{ng} / \mathrm{mL}$, and serum lactate 4.0 $\mathrm{mmol} / \mathrm{L}$. Arterial blood gas on 50\% inspired oxygen revealed $\mathrm{pH}$ 7.20, partial pressure of carbon dioxide 51.3 $\mathrm{mmHg}$, partial pressure of oxygen $98.6 \mathrm{mmHg}$, and bicarbonate $19.5 \mathrm{mEq} / \mathrm{L}$. Twelve-lead electrocardiogram revealed sinus tachycardia with no apparent ST-segment or T-wave changes. Computed axial tomography of the head did not show any acute intracranial process, and a chest X-ray revealed bilateral basal opacifications.

Physical examination of the eyes noted minimally reactive but equal and round pupils. Cardiac exam revealed tachycardia with a regular rhythm, no murmurs, and no gallops. The lungs were clear to auscultation and percussion. The neurological examination of the patient demonstrated unintelligible speech, complete lack of cooperation or orientation, myoclonic jerks in the upper extremities, and spastic lower extremities. Based upon the Modified Ashworth Scale, his level of spasticity graded as a " 3 " in the upper extremities and a " 4 " in the lower extremities. Further exam elicited clonus in the bilateral lower extremities along with $3+$ bilateral patellar reflexes and $4+$ sustained bilateral Achilles reflexes.

After this preliminary evaluation, the differential diagnosis included sepsis, meningitis, neuroleptic malignant syndrome, seizure disorder, and autonomic dysreflexia, but further elicitation of patient history brought intrathecal baclofen withdrawal to the forefront. The patient's implanted Medtronic SynchroMed II intrathecal infusion system had provided continuous delivery of baclofen and apparent symptomatic relief for a three-year period. However, he missed his scheduled pump refill appointment four weeks prior to this emergent presentation and had ignored the audible pump alarm for three weeks.

Initial treatment in the emergency department included a total of $16 \mathrm{mg}$ of intravenous lorazepam to reduce the patient's agitation. At the outside facility, he had received a total of $25 \mathrm{mg}$ of intravenous lorazepam and 5 mg of intravenous midazolam for refractory agitation. Admission orders thus called for a dosage of lorazepam 1 to $2 \mathrm{mg}$ intravenously every one hour as needed. The patient was also started on baclofen $40 \mathrm{mg}$ every eight hours per nasogastric tube on a scheduled basis. In addition, the patient began scheduled regimens of intravenous azithromycin, levofloxacin, and vancomycin; cultures later returned negative with subsequent stoppage of antibiotics. In the first twenty-four hours, the patient received a total of seven liters of crystalloid solution and required low-dose norepinephrine via continuous infusion because of hypotension. This decision for aggressive hydration also recognized his elevated creatine kinase level and its likely contribution to concomitant acute renal failure.

On hospital day two, the patient's primary medical team made the decision to intubate the patient because of his inability to protect the airway. Electroencephalogram (EEG) showed diffuse intermittent medium- to high-voltage theta and delta activities with the absence of a normal waking or sleeping pattern. This markedly abnormal result was consistent with severe non-specific diffuse cerebral dysfunction, raising the possibility of anoxic brain injury given the patient's hypotensive presentation. In- 
terrogation of the patient's intrathecal pump revealed a reservoir volume of $0 \mathrm{~mL}$ of baclofen $(2000 \mathrm{mcg} / \mathrm{mL})$; the pump was then refilled with $40 \mathrm{~mL}$ of baclofen (2000 $\mathrm{mcg} / \mathrm{mL}$ ) and programmed for simple continuous infusion at a rate matching his previous dosing of $224.9 \mathrm{mcg} /$ day. At this time, the previously ordered baclofen per nasogastric tube was discontinued; the patient received a total of one $40 \mathrm{mg}$ dose. The patient also received dantrolene $100 \mathrm{mg}$ intravenously every four hours for a 24hour period to help modulate the peripheral spasticity. Sedation while intubated was maintained with midazolam $1 \mathrm{mg} / \mathrm{h}$ and fentanyl $0.5 \mathrm{mcg} / \mathrm{kg} / \mathrm{h}$. These continuous infusions largely calmed his agitation, as he required a total of $2 \mathrm{mg}$ of bolused intravenous lorazepam in the twenty-four hours following admission and no further boluses thereafter. The patient's low-grade fever subsided on day two and further elevations did not occur. Creatine kinase levels reached a peak of $4873 \mathrm{ng} / \mathrm{mL}$ on hospital day two and descended steadily thereafter, correlating with decreasing serum creatinine levels, which reached $0.9 \mathrm{mg} / \mathrm{dL}$ on hospital day four. Reassessment of spasticity using the Modified Ashworth Scale on day four revealed scores of "2" in both the upper and lower extremities.

The patient continued to make occasional flexing motions with his upper extremities bilaterally through hospital day eight in a manner similar to, though less dramatic than, his presenting arm movements. On hospital day seven, the patient began to open his eyes to stimuli, though he neither tracked movement nor followed commands. The managing team thus stopped all sedative medications in an attempt to further awaken the patient, and he began to track movement with his eyes and follow commands on hospital day nine. The patient was extubated successfully on hospital day ten and oxygenated well on room air by hospital day eleven. At that time, the patient answered questions appropriately and reached near-baseline mental status. The patient was discharged home on hospital day fifteen with apparent return to baseline mentation.

\section{Discussion}

Variable presentation characterizes intrathecal baclofen withdrawal in cases cited in the literature. Classically, the withdrawal syndrome symptomatology includes agitation, restlessness, delusions, hallucinations, psychosis, confusion, hypertonicity, seizure activity, blood pressure lability, and fever $[16,17]$. This may progress to rhabdomyolysis, hypotension, coagulopathy, disseminated intravascular coagulation, renal failure, hepatic failure, respiratory failure, cardiac dysrhythmias, cardiac arrest, and death [18]. Symptoms appear within $12-72$ hours after interruption of therapy and the pathophysiology may relate to decreased inhibitory tone previously mediated by the effects of $G_{A B A}$ receptors, downregulation of $\mathrm{GABA}_{\mathrm{A}}$ receptors, and a resultant release of excitatory neurotransmitters $[16,17]$. However, elucidating the precise cause of these symptoms on initial presentation may prove difficult due to the patient's likely inability to provide a reliable medical history [19]. The presentation may initially imitate meningitis, sepsis, autonomic dysreflexia, neuroleptic malignant syndrome, and malignant hyperthermia [19].

Currently, no specific pharmacologic treatment protocol for acute intrathecal baclofen withdrawal exists. Treatment methods traditionally have included oral baclofen, though its slow onset of action (3 - 4 days) and time to reach peak effect (5 - 10 days) make its effectiveness questionable given the rapidity of the appearance of acute intrathecal withdrawal symptoms [20]. Rather, as employed in our case, treatment should focus on restoration of drug administration intrathecally at the pre-withdrawal dosage [21].

Other adjunctive medications also demonstrate usefulness in intrathecal baclofen withdrawal, especially with respect to the syndrome's muscle rigidity. Intravenous benzodiazepines, including via continuous infusion, merit strong consideration, especially in the presence of seizures, presuming availability of ventilatory and cardiovascular support [16,21]. Benzodiazepines help restore neuronal inhibition previously provided by intrathecal baclofen, acting on $\mathrm{GABA}_{\mathrm{A}}$ receptors to relieve muscle rigidity and spasticity [21]. Other pharmacologic agents to consider include propofol, which also has presynaptic $\mathrm{GABA}_{\mathrm{A}}$ activity [20]. Cyproheptadine antagonizes serotonin, which may help to attenuate the excess serotonergic excitatory neuronal activity believed to occur during baclofen withdrawal [20]. In the presence of severe muscle spasticity, dantrolene may also prove useful; its mechanism of blocking calcium release from sarcoplasmic reticulum in skeletal muscles may help decrease muscular excitation and contraction [20,21]. Tizanidine, an $\alpha_{2}$-adrenergic agonist, may also help relieve muscle spasticity by decreasing excitatory input at the level of the spinal cord [20]. Opiates may also have utility given the likely neurophysiologic relationship between $G_{A B A}$ receptor- and opiate receptor-mediated pathways; for example, morphine inhibits GABAergic neuronal impulses via activation of $\mu$-opioid receptors [22]. In addition, studies have shown that baclofen inhibits morphine-induced motor activity via interaction with midbrain $\mathrm{GABA}_{\mathrm{B}}$ receptors [23]. Given the apparent neurochemical coupling between opiates and baclofen, the role of opiates in intrathecal baclofen withdrawal treatment certainly merits further study. 
The treatment of delirium in this setting also includes a number of pharmacologic options. Haloperidol, commonly used to treat delirium in intensive care settings, may cause hypotension. In addition, it may also lower the seizure threshold, with one study revealing a $23 \%$ incidence of abnormal EEG findings with the use of haloperidol $[20,24]$. Given the overall propensity of neuroleptics and antipsychotics to induce EEG abnormalities, extreme caution with their use should be exercised with concomitant adjuvant sedatives [25]. The highest risk of invoking EEG abnormalities exists with clozapine and olanzapine [25].

Withdrawal from intrathecal baclofen remains a lifethreatening entity as evidenced by our case and numerous other case reports [19-21]. Successful treatment appears to center around restoration of intrathecal baclofen levels and the use of multiple adjuvant medications to combat accompanying symptoms. Most important to successful recovery from this withdrawal syndrome remains early recognition and a high index of suspicion in the presence of any suggestive patient history. Our patient fortunately benefited from such awareness and subsequently recapitulated his previous lifestyle.

\section{Acknowledgements}

We thank Dr. Eugene E. Fibuch for comments and proofreading of this manuscript.

\section{REFERENCES}

[1] G. M. L. Reis and I. D. G. Duarte, "Baclofen, an Agonist at Peripheral GABA $\mathrm{B}_{\mathrm{B}}$ Receptors, Induces Antinociception via Activation of TEA-Sensitive Potassium Channels," British Journal of Clinical Pharmacology, Vol. 149, No. 6, 2006, pp. 733-739. doi:10.1038/sj.bjp.0706898

[2] N. G. Bowery, A. L. Hudson and G. W. Price, "GABA and $\mathrm{GABA}_{\mathrm{B}}$ Receptor Site Distribution in the Rat Central Nervous System,” Neuroscience, Vol. 20, No. 2, 1987, pp. 365-383. doi:10.1016/0306-4522(87)90098-4

[3] D. C. M. Chu, R. L. Albin, A. B. Young and J. B. Penney, "Distribution and Kinetics of $\mathrm{GABA}_{\mathrm{B}}$ Binding Sites in Rat Central Nervous System: A Quantitative Autoradiographic Study,” Neuroscience, Vol. 34, No. 2, 1990, pp. 341-357. doi:10.1016/0306-4522(90)90144-S

[4] M. Chebib and G. A. R. Johnston, "GABA-Activated Ligand Gated Ion Channels: Medicinal Chemistry and Molecular Biology,” Journal of Medicinal Chemistry, Vol. 43, No. 8, 2000, pp. 1427-1447. doi:10.1021/jm9904349

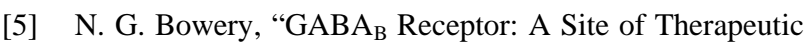
Benefit," Current Opinion in Pharmacology, Vol. 6, No. 1, 2006, pp. 37-43. doi:10.1016/j.coph.2005.10.002

[6] A. R. Calver, A. D. Medhurst, M. J. Robbins, K. J. Charles, M. L. Evans, D. C. Harrison, M. Stammers, S. A. Hughes, G. Hervieu, A. Couve, S. J. Moss, D. N. Middle- miss and M. N. Pangalos, "The Expression of $\mathrm{GABA}_{\mathrm{B} 1}$ and $\mathrm{GABA}_{\mathrm{B} 2}$ Receptor Subunits in the CNS Differs from That in Peripheral Tissues," Neuroscience, Vol. 100, No. 1, 2000, pp. $155-170$. doi:10.1016/S0306-4522(00)00262-1

[7] M. Slonimski, S. E. Abram and R. E. Zuniga, "Intrathecal Baclofen in Pain Management," Regional Anesthesia and Pain Medicine, Vol. 29, No. 3, 2004, pp. 269-276. doi:10.1016/j.rapm.2004.01.005

[8] J. C. Hsieh and R. D. Penn, "Intrathecal Baclofen in the Treatment of Adult Spasticity,” Neurosurgical Focus, Vol. 21, No. 2, 2006, pp. 1-6. doi:10.3171/foc.2006.21.2.6

[9] P. K. Rawlins, "Intrathecal Baclofen Therapy over 10 Years,” Journal of Neuroscience Nursing, Vol. 36, No. 6, 2004, pp. 322-327. doi:10.1097/01376517-200412000-00005

[10] N. G. Bowery, B. Bettler, W. Froestl, J. P. Gallagher, F. Marshall, M. Raiteri, T. I. Bonner and S. J. Enna, "International Union of Pharmacology. XXXIII. Mammalian $\gamma$-Aminobutyric Acid $_{\mathrm{B}}$ Receptors: Structure and Function,” Pharmacological Reviews, Vol. 54, No. 2, 2002, pp. 247-264. doi:10.1124/pr.54.2.247

[11] R. C. Riley, J. A. Trafton, S. I. Chi and A. I. Basbaum, "Presynaptic Regulation of Spinal Cord Tachykinin Signaling via $\mathrm{GABA}_{\mathrm{B}}$ but Not GABA $\mathrm{A}$ Receptor Activation," Neuroscience, Vol. 103, No. 3, 2001, pp. 725-737. doi:10.1016/S0306-4522(00)00571-6

[12] M. Iyadomi, I. Iyadomi, E. Kumamoto, K. Tomokuni and M. Yoshimura, "Presynaptic Inhibition by Baclofen of Miniature EPSCs and IPSCs in Substantia Gelatinosa Neurons of the Adult Rat Spinal Dorsal Horn,” Pain, Vol. 85, No. 3, 2000, pp. 385-393. doi:10.1016/S0304-3959(99)00285-7

[13] R. Hering-Hanit, "Baclofen for Prevention of Migraine," Cephalalgia, Vol. 19, No. 6, 1999, pp. 589-591. doi:10.1046/j.1468-2982.1999.019006589.x

[14] P. Fadda, M. Scherma, A. Fresu, M. Collu and W. Fratta, "Baclofen Antagonizes Nicotine-, Cocaine-, and Morphine-Induced Dopamine Release in the Nucleus Accumbens of Rat,” Synapse, Vol. 50, No. 1, 2003, pp. 1-6. doi:10.1002/syn.10238

[15] M. Sabetkasai, R. Doost-Mohammady and M. R. Zarrindast, "Opposite Influences of Different Adrenoceptors on Baclofen-Induced Antinociception in Mice,” Pharmacology \& Toxicology, Vol. 80, No. 1, 1997, pp. 6-10. doi:10.1111/j.1600-0773.1997.tb00276.x

[16] R. Olmedo and R. S. Hoffman, "Withdrawal Syndromes," Emergency Medicine Clinics of North America, Vol. 18, No. 2, 2000, pp. 273-288. doi:10.1016/S0733-8627(05)70124-3

[17] J. Santiago-Palma, E. D. Hord, R. Vallejo, J. Trella and S. U. Ahmed, "Respiratory Distress after Intrathecal Baclofen Withdrawal," Anesthesia \& Analgesia, Vol. 99, No. 1, 2004, pp. 227-229. doi:10.1213/01.ANE.0000121347.11127.99

[18] L. B. Green and V. S. Nelson, "Death after Acute Withdrawal of Intrathecal Baclofen: Case Report and Literature Review," Archives of Physical Medicine and Reha- 
bilitation, Vol. 80, No. 12, 1999, pp. 1600-1604. doi:10.1016/S0003-9993(99)90337-4

[19] L. W. Kao, Y. Amin, M. A. Kirk and M. S. Turner, "Intrathecal Baclofen Withdrawal Mimicking Sepsis," The Journal of Emergency Medicine, Vol. 24, No. 4, 2003, pp. 423-427. doi:10.1016/S0736-4679(03)00039-8

[20] J. C. Ross, A. M. Cook, G. L. Stewart and B. G. Fahy, "Acute Intrathecal Baclofen Withdrawal: A Brief Review of Treatment Options," Neurocritical Care, Vol. 14, No. 1, 2011, pp. 103-108. doi:10.1007/s12028-010-9422-6

[21] R. J. Coffey, T. S. Edgar, G. E. Francisco, V. Graziani, J. M. Meythaler, P. M. Ridgely, S. A. Sadiq and M. S. Turner, "Abrupt Withdrawal from Intrathecal Baclofen: Recognition and Management of a Potentially Life-Threatening Syndrome," Archives of Physical Medicine and Rehabilitation, Vol. 83, No. 6, 2002, pp. 735-741. doi:10.1053/apmr.2002.32820

[22] C. R. Hansen, J. L. Gooch and T. Such-Neibar, "Prolonged, Severe Intrathecal Baclofen Withdrawal Syndrome: A Case Report," Archives of Physical Medicine and Rehabilitation, Vol. 88, No. 11, 2007, pp. 1468-1471. doi:10.1016/j.apmr.2007.07.021

[23] K. A. Leite-Morris, E. Y. Fukudome, M. H. Shoeb and G. B. Kaplan, " $G A B A_{B}$ Receptor Activation in the Ventral Tegmental Area Inhibits the Acquisition and Expression of Opiate-Induced Motor Sensitization," Journal of Pharmacology and Experimental Therapeutics, Vol. 308, No. 2, 2004, pp. 667-678. doi:10.1124/jpet.103.058412

[24] B. L. Amann, O. Pogarell, R. Mergl, G. Juckel, H. Grunze, C. Mulert and U. Hegerl, "EEG Abnormalities Associated with Antipsychotics: A Comparison of Quetiapine, Olanzipine, Haloperidol and Healthy Subjects," Human Psychopharmacology: Clinical and Experimental, Vol. 18, No. 8, 2003, pp. 641-646. doi:10.1002/hup.537

[25] F. Centorrino, B. H. Price, M. Tuttle, W. Bahk, J. Hennen, M. J. Albert and R. J. Baldessarini, "EEG Abnormalities during Treatment with Typical and Atypical Antipsychotics," The American Journal of Psychiatry, Vol. 159, No. 1, 2002, pp. 109-115. doi:10.1176/appi.ajp.159.1.109 